\title{
HARM overview and its application: some practical examples
}

\author{
Marjolein Douwes and Heleen de Kraker \\ TNO,P.O.Box 718,2130AS Hoofddorp,The Netherlands; marjolein.douwes@tno.nl
}

\begin{abstract}
The Hand Arm Risk Assessment Method (HARM 1.0) has been developed for occupational health officers to perform risk assessments of developing arm, neck or shoulder pain during hand arm tasks. The tool can also help in finding solutions for risk reduction and estimating their effect on the risk level. In this paper the status of affairs and the practical application of HARM is described. The usage of HARM is explained and illustrated with the risk assessment of a specific hand arm task. In addition, the experiences with the application of HARM by a stone factory in The Netherlands are described.
\end{abstract}

Keywords: MSD, risk assessment, prevention officer, practical application, work place analysis.

\section{Introduction}

To accommodate Dutch companies in their obligation to protect their employers from health and safety risks, the Ministry of Social Affairs and Employment provides them with freely available risk assessment tools. One of these tools is the Hand Arm Risk Assessment tool (HARM 1.0). This tool has been developed in 2007-2009 for the risk assessment of developing arm, neck or shoulder pain. In 2009 HARM has been made freely available in The Netherlands. Although the main target group are companies, who have a need for quick and simple risk assessment tools, the tool can also be used by occupational health consultants, ergonomists and designers.

The development process and results of a field study have been described previously [2]. Moreover, the results of a reliability and validity study have been described in [3]. This paper describes the current status of the Hand Arm Risk Assessment Method (HARM) and its application in practice. First, a short description of the purpose and scope of the tool is given.

\section{Purpose and scope of HARM}

The HARM can be used for the risk assessment of developing arm-, neck- or shoulder pain from performing hand-arm tasks. Moreover, the tool can help in finding the main causes of the risks, possible measures that may reduce the risks and the effect that these measures are expected to have.

Hand-arm tasks are tasks in which primarily the hands and arms are active and the legs and torso only to a lesser degree. Examples of hand-arm tasks are: assembly or disassembly tasks, hairdresser's tasks (washing, cutting, drying), sorting, packaging and sanding woodwork.

HARM is to be used for all hand-arm tasks that:

- are performed for at least 1 hour per day

- have force exertions that don't exceed $6 \mathrm{~kg} / 60 \mathrm{~N}$ per hand.

An exception is computer work; for this type of work other more suitable methods exist.

Potential users are those who are responsible for a company's working conditions, such as prevention officers, occupational health officers, personnel officers, HRM staff or - in small companies - the managing director himself. The method may also be useful to health and safety experts and working conditions services. The method does not require any specific knowledge or special training.

HARM is being applied on task level and therefore gives risk estimations for the group of all employees performing that task. It is important to realize that also other (hand-arm or other type of) tasks may be hazardous and thus, need to be evaluated. For each task a separate assessment needs to be made. HARM 
does not offer a way to perform a combined tasks analysis or calculate a daily work load.

\section{The application of HARM}

HARM starts with a short description of the purpose and scope of the method. For data collection the user makes observations of the task at the workplace or from a video recording of the task and by time and frequency recordings. Some of the information can be collected by asking the employee.

The risk estimation consists of 7 steps, that are explained below. To illustrate the method, the steps of a risk assessment of cutting hair by a hairdresser are shown. In each step of HARM a help-text explains the user how to collect the information that is needed. Moreover, in a video instruction each step is explained in detail, using different examples.

Step 1. Hand arm tasks, task duration and breaks. In the first step the user needs to identify the hand arm task(s) to be analyzed, the number of days a week and hours a day the task is performed and whether or not sufficient breaks (at least 7.5 minutes rest or other type of work every 1.5 hours of cutting) are being taken. This information is often known by the user or needs to be asked to the employees who perform the task. From these data the 'task duration score' is calculated.
Example: A hairdresser performs the task 'cutting' for 4 days a week and 6 hours a day; the number of breaks or other tasks (with other physical load) is sufficient because of other tasks that are being performed in between cutting hair. The task duration score in this case is 4.5.

Step 2: Most active hand/arm. The risk assessment is performed for only one hand/arm, i.e. the hand that appears to perform the greater effort. This is the one that either exerts the higher forces or makes more movements per minute. If both hands appear to be equally active, but in different ways (e.g. if one hand performs greater force exertions but the other makes more movements), a separate risk assessment for each hand is to be made and the highest risk score is to be used for the risk evaluation.

Example: In case of the hairdresser the risk assessment is performed only for the hand that is actually being used for cutting (unless both hands are being used).

Step 3: Force exertion. For force exertion a table is being used in which the force level, frequency of force exertion and duration of force exertion are combined (see figure 3). The force level is divided into the following categories: less than $100 \mathrm{~g}, 100 \mathrm{~g}$ $1 \mathrm{~kg}, 1-3 \mathrm{~kg}, 3-6 \mathrm{~kg}$ and peak force (hitting).

\begin{tabular}{|c|c|c|c|c|c|c|c|}
\hline \multirow[t]{2}{*}{$\begin{array}{c}\text { Description of force } \\
\text { exertion }\end{array}$} & \multirow[t]{2}{*}{ Amount of force } & \multicolumn{3}{|c|}{$\begin{array}{c}\text { Duration of the force } \\
\text { exertion } \\
\text { (in sec. per min.) }\end{array}$} & \multicolumn{3}{|c|}{$\begin{array}{l}\text { Frequency: number } \\
\text { of force exertions } \\
\text { (per min.) }\end{array}$} \\
\hline & & $<4$ & $4-30$ & $30-60$ & $<4$ & $4-30$ & $\geq 30$ \\
\hline combing hair & very low force & - & 0 & 0 & 0 & 0 & - \\
\hline cutting hair & average force & $\bullet$ & 0 & 0 & 0 & 0 & $\bullet$ \\
\hline
\end{tabular}

Fig. 1. Screenshot of step 3: the amount of force, duration and frequency of all force exertions need to be indicated 
For the duration of force exertion there are three options: $<4,4-30$ and 30-60 seconds per minute. The frequency of force exertion also has three categories: $<4,4-30$ and $\geq 30$ times a minute. The average force duration and frequency within a minute need to be recorded using a stopwatch.

The combination of both the level and duration and the level and frequency lead to a score. All the forces that are applied during the task, need to be scored this way. The highest of these scores is the result of this step: the 'force score'.

Example: there are two force exertions (with the same hand) during cutting: the actual cutting (small force, 0-4 s per force exertion, frequency higher than 30 times /min.) and combing the hair (very small force, 0-4 s per force exertion, frequency higher than 30 times /min.). The force score is 4.

Step 4: Postures. There are two types of postures to be scored:

(I) Neck/shoulder postures:

- flexion, lateral flexion or extension of the neck

- combined flexion and rotation of the neck

- combined extension and rotation of the neck

- antero (forward) position of the head

- unsupported flexion or abduction of the shoulder $\left(>20^{\circ}\right)^{*}$ and

- elevation of the shoulders.

(II) Lower arm/wrist postures:

- maximum flexion or extension of the elbow

- pro- or supination (more than $\left.40^{\circ}\right)^{*}$ of the lower arm

- either ulnar/radial deviation (more than $\left.10^{\circ}\right)^{*}$ or flexion/extension (more then $\left.15^{\circ}\right)^{*}$ of the wrist.

*These angles are not mentioned explicitly in HARM but they were used to illustrate the postures in the photographs.

For each of these postures the average relative duration (three categories: $0-10 \%, 10-50 \%,>50 \%$ of the task duration) needs to be estimated. To do this the duration of these postures is preferably recorded during repeated samples of the task. An example of the result is given in figure 2 .

This step results in two risk scores: (1) the highest score for all neck/upper arm postures and (2) the highest score for all lower arm/wrist postures.

Example: during the cutting task of the hairdresser then head is tilted 10-50\% of the task duration and the upper arm is elevated for 10-50\% of the task duration, leading to a score of 2.5. Both rotation of the forearm and bending of the wrist (in two directions, see fig. 2) occur for more than $50 \%$ of the task duration. The corresponding score for these lower arm/wrist postures is 3 .

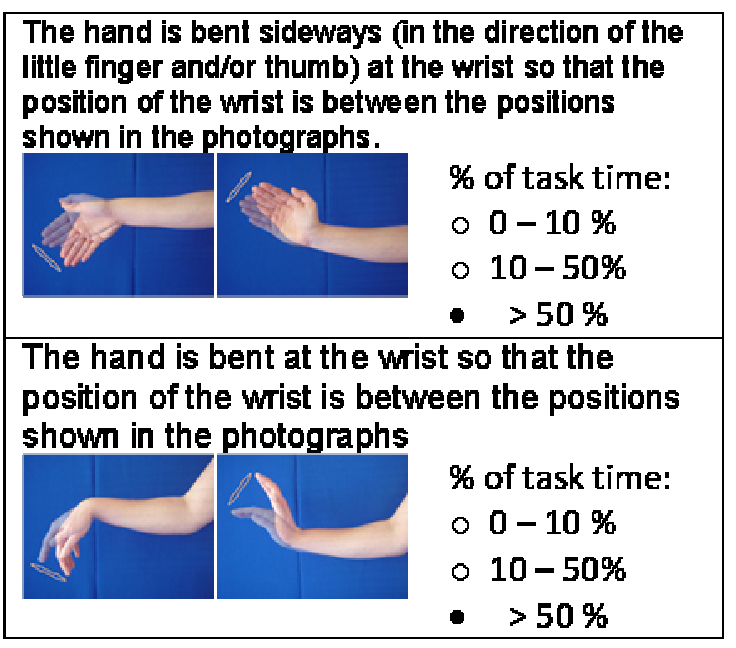

Fig. 2. Screenshot of step 4B of HARM: the relative duration of awkward postures needs to be indicated..

Step 5: Using vibrating tools. Both quantitative and qualitative categories of hand-arm vibration from powered tools are included in the tool. If the vibration intensity is known (from measurements or manual), this can be evaluated using the quantitative table. If this information is not available the user needs to estimate the vibration by a combination of observations of the task, questions to the worker and touching the arm of the worker (see table 1). In addition, the duration of the exposure per day has to be given as well (0-4 or 4-8 hours a day).

Example: For the cutting task of the hairdresser this step results in a vibration score of 0 , because no vibrating tools are being used when using scissors (and no trimmer). 
Table 1

Descriptions of the 4 categories of vibrations to be used for estimating the vibration intensity.

\begin{tabular}{|c|c|}
\hline $\begin{array}{l}\text { Intensity of } \\
\text { vibrations }\end{array}$ & Descriptions for practitioners \\
\hline $\begin{array}{l}<2,5 \\
\mathrm{~m} / \mathrm{s} 2\end{array}$ & $\begin{array}{l}\text { Hardly any vibration, or no vibrations } \\
\text { perceived by the user or visible to the } \\
\text { assessor }\end{array}$ \\
\hline $\begin{array}{r}\leq 2,5-5 \\
\mathrm{~m} / \mathrm{s} 2\end{array}$ & $\begin{array}{l}\text { Vibrations not visible, but perceived by } \\
\text { the user (quivering sensation) }\end{array}$ \\
\hline $\begin{array}{r}\leq 5-10 \\
\mathrm{~m} / \mathrm{s} 2\end{array}$ & $\begin{array}{l}\text { Vibrations just visible on the lower } \\
\text { arm/hand, clearly perceived by the user }\end{array}$ \\
\hline $\begin{array}{l}\geq 10 \\
\mathrm{~m} / \mathrm{s} 2\end{array}$ & $\begin{array}{l}\text { The hands, arms or shoulders can be } \\
\text { clearly seen to vibrate and vibrations } \\
\text { are clearly perceived by the user }\end{array}$ \\
\hline
\end{tabular}

Step 6: Other factors. Five other possible risk factors have been included in this step. These are:

- set breaks times are taken by the employee (as opposed to breaks at the employee's discretion)

- unfavourable environmental conditions (e.g., cold and/or draught)

- disruption to concentration (only if work requires concentration)

- poor contact with material and tools, e.g. as a result of wearing gloves

- having to perform a precision task with the hands or fingers.

The risk score depends on the number of factors present, i.e. 1 point if only one factor is present, 2 points if two or more factors are present.

Example: In case of the hairdresser the score is 1, because of set breaks times.

Step 7: Risk evaluation. To calculate the overall risk score the sum of the scores from step 3-6 is multiplied with the 'task duration score' of step 1 . This final score is evaluated using a traffic light model. In this model green $(<25$ points) means that the tasks does not pose an increased risk of developing arm, neck or shoulder pain, amber (25-50 points) means that the task does pose an increased risk and red ( $\geq 50$ points) means that a significantly increased risk is present from the task.

Apart from this result the tool also shows:
- Main causes of the risk: To be able to identify the main causes of an increased risk, the risk scores of the separate factors (steps) are presented as well.

- General recommendations for risk reduction: Some general recommendations are given, targeting each of the separate factors. It is recommended that a company starts with measures that tackle the risk factor with the highest score. If work related complaints already exist, measures should be taken irrespective of the risk evaluation.

Example: for the hairdresser the final risk score is 4.5 (task duration score) $x$ 10,5 (sum of scores from step 2 to 6) $=47$. This is a score in the amber (almost red) category and means that the tasks poses an increased risk of developing arm, neck or shoulder pain. The scores per step show that the task duration, force and the lower arm/wrist postures are the most important risk factors. Therefore finding measures to reduce these scores would be advisable.

\begin{tabular}{|lc|}
\hline Step & Riskscore \\
\hline Force (step 3) & 4 \\
\hline Posture low er arm /wrist (step 4b) & 3 \\
\hline Posture neck/shoulder (step 4a) & 2,5 \\
\hline Other factors (step 6) & 1 \\
\hline Vibration (step 5) & 0 \\
\hline Task duration (step 1) & 4,5 \\
\hline $\begin{array}{l}\text { Total risk s core (sum all scores tim es task } \\
\text { duratlon) }\end{array}$ & 47 \\
\hline
\end{tabular}

Fig. 3. Screenshot of step 7, overview of scores per step (in decreasing risk order) and the total risk score

\section{Experiences with HARM of a Dutch stone factory}

\subsection{Motivation of using HARM}

Stone factory Linssen in The Netherlands has started to use HARM in 2010 after a visit of the Labour Inspectorate in the factory in which HARM was applied. For two of the evaluated hand-arm tasks the results showed 'a seriously increased risk of developing arm, neck or shoulder pain' (red traffic light). The managing director of the company was surprised to see this result, because of the low sick leave in the company (less than $3 \%$ in 2010) and repeated the evaluation, using HARM himself. The manager had more detailed information on the tasks (as input for HARM) that was not available to the Labour Inspec- 
torate. The re-evaluation resulted in a shift from a red to an amber traffic light (an increased risk of arm, neck or shoulder pain). A secondary gain from using HARM was that the manager discovered important new knowledge and ideas on risk reduction in these tasks.

\subsection{The task that was evaluated}

Twelve out of twenty employees in the factory have tasks in which they sort and stack stones by hand. The first time is when the stones are dried. Employees stand at an assembly line, pick up two stones in both hands and inspect them on size and fractures. Then they stack them onto another line. After the final baking process in a tunnel oven the stones are being stacked manually on pallets for the customers. Although this company has an active policy on occupational health and has made a lot of improvements - e.g. an ergonomic workstation - these manual tasks can not be replaced by automatic systems.

The two owners of the company both performed an evaluation of the two hand arm tasks using HARM. Their experience is that the method is easy to use and that "anybody can use HARM after two hours of preparations and reading the manual". To be able to make a detailed analysis of the work tasks without disturbing the employees they made video recordings of the work tasks. Results of both assessments were the same: an amber traffic light. These results were shown to an ergonomist of the Technical Centre of Ceramic Industry (TCKI), who confirmed the conclusions. This proved to them that the tool worked well.

According to these users, "HARM not only results in a risk evaluation, but also gives you some direction to risk reduction measures and the expected effects of these measures. Moreover, the video analysis revealed other relevant hazards, i.e. that the workers sometimes tended to stand on their toes". Although this is not relevant for HARM, it is a relevant observation for risk reduction in a more general sense. Moreover, by using HARM the company gained insight in the effect of task rotation, and more specifically of the effect of rotating between amber and green tasks. Manager: "The workers themselves took the initiative to rotate these tasks every ten minutes. The HARM results show that they were right in doing so." This was a real eye-opener for them.
The work analysis has also resulted in the decision to buy another lifting device to improve the working posture (upper arm elevation).

\subsection{Overall opinion on HARM use}

The experiences of the managing director are that HARM is easy to use, that it gives a quick and thorough insight in the risks of hand arm tasks and that it helps in finding solutions to reduce the risks.

His advice to other HARM users is to perform task analyses from video. A thorough analysis of the work tasks helps to see where to improve the working conditions, even if they do not affect the HARM score. A note to the HARM developers is to increase the sensitivity of the final risk score of HARM, although he understands that this may affect the simplicity and time needed for the risk evaluation.

\section{HARM: current and future activities}

In 2008 the concurrent validity and inter tester reliability of the HARM have been studied. Results of this study have been described in [2]. These results have been used to improve the tool, mainly with respect to the usability. Help text was improved and a video instruction for each step of the tool was added. In this video instructions different examples were used to explain the risk factors and the methods to be used to measure or estimate the exposure level.

Currently, two studies are being performed:

(1) The predictive validity of HARM is being studied. In this study exposure and health effect data from a prospective study on risk factors for MSD (the SMASH study, described in [1]) are being used. The validity of the underlying factors of each step of HARM, e.g. force exertion, posture duration etc. will be studied as well; this information will be used for further improvement of the validity of the tool. The results of this study are expected to be available in the end of 2011.

(2) The number of users of HARM 1.0 are being monitored by the hosting party of the web version. The number of users using the paper version is not known. The usability is being evaluated by a short questionnaire that visitors of HARM are asked to fill in after they clicked on the link to HARM. Results 
of a first group of 17 users show that there are few problems (in step 1 and 3 only) with applying the method and that $82 \%$ of these users find it useful to apply the method. The overview of results gives appropriate information according to $71 \%$, the method leads to a useful risk assessment according to $82 \%$ and it has led to a plan of action for risk reduction in $59 \%$ of the cases. Points of improvement that were mentioned are the lack of more specific grips/ positions of hands, fingers and thumb (mentioned 3 times) and the instinctive dominance of the task duration score especially for high repetition tasks (mentioned once).

For 2012-2014 the following activities are planned:

- A reliability and validity study on the method that was developed for step 5 (using vibrating tools) for a wide variety of vibration levels (in our study we have tested only four different conditions);

- Development of HARM 2.0, based on results of the validity study and usability results.

- Further implementation and stimulation of the usage of the tool. This activity will be done in combination with the implementation of the other assessment instruments, especially the level I checklist and the level II Working Posture Risk Assessment Tool (WRAP). Main goal is to introduce the methods to the target group and stimulate their use. Several communication methods will be used, e.g. distribution of flyers and organizing presentations and workshops on the method. The long term goals are better risk assessments, an increase of interventions to reduce the risks posed by hand arm tasks and subsequently a decrease in arm, neck and shoulder complaints.

- Monitoring the usage and usability of HARM (ongoing)

- Re-establish the validity and reliability of the HARM 2.0.

\section{References}

[1] Ariëns GA, Bongers PM, Douwes M, Miedema MC, Hoogendoorn WE, Wal G van der, et al. Are neck flexion, neck rotation, and sitting at work risk factors for neck pain? Result of a prospective cohort study. Occup Environ Med. 2001;58:200207.

[2] Douwes M, Kraker H. de, Hand Arm Risk assessment Method (HARM), a new practical tool. $17^{\text {th }}$ world congress on Ergonomics, August 9-14, Beijing, 2009.

[3] Kraker H. de, Douwes M. The development of a practical tool for risk assessment of manual work - the 'HAT-tool', 40th Annual Conference of the Nordic Ergonomics Society, Iceland, 2008. 